\title{
Discursos Sobre a Mutilação Genital Feminina e Seus Reflexos na Contemporânea Sociedade Jurídica Internacional
}

\author{
José Humberto de Alencar Filhol ; Miguel Ângelo Silva de Melo ${ }^{2}$;
}

\begin{abstract}
Resumo: A presente pesquisa tem como tema a análise da prática da mutilação genital feminina e seus reflexos na contemporânea sociedade jurídica internacional. As premissas que fundamentam o trabalho encontram espaço nos discursos proferidos na teoria geral dos direitos humanos, sob o foco da universalidade e da relatividade dos direitos e de tais práticas culturais. Esta pesquisa fez uso de métodos qualitativos/bibliográficos como instrumentos para análise. Quanto à abordagem, esta se caracteriza como pesquisa qualitativa, através da qual será registrada a intepretação das ideias, buscando entender os problemas apresentados pelos assuntos abordados e procurando adequar soluções para essas problemáticas. Finalmente, conclui-se que a Dignidade da Pessoa Humana está concatenada com outros valores, como a justiça, a vida, a liberdade, a igualdade, a segurança e a solidariedade, as quais inspiram ações concretas, dignificam os que se propõe a alcançá-los, respaldando os diversos ordenamentos jurídicos, dando concretude e respaldo ao combate a injustiças, e atos cruéis, desumanos ou degradantes.
\end{abstract}

Palavras-chave: Mutilação Genital Feminina. Teoria Relativista. Teoria Universalista. Dignidade da Pessoa Humana. Ordenamentos Jurídicos Internacionais.

\section{Discussions on Female Genital Mutilation and its Reflections in Contemporary International Legal Society ${ }^{3}$}

\begin{abstract}
The present research has as its theme the analysis of the practice of female genital mutilation and its reflexes in the contemporary international juridical society. The premises that underlie the work find space in the discourses given in the general theory of human rights, under the focus of universality and relativity of rights and such cultural practices. This research made use of qualitative / bibliographic methods as tools for analysis. Regarding the approach, this is characterized as a qualitative research, through which the interpretation of ideas will be recorded, seeking to understand the problems presented by the subjects addressed and seeking to adapt solutions to these problems. Finally, it is concluded that the Dignity of the Human Person is linked to other values, such as justice, life, liberty, equality, security and solidarity, which inspire concrete actions, dignify those who propose to achieve them, supporting the various legal systems, giving concreteness and support to the fight against injustice, and cruel, inhuman or degrading acts.
\end{abstract}

Keywords: Female Genital Mutilation. Relativistic Theory. Universalist Theory. Dignity of human person. International Legal Arrangements.

\footnotetext{
${ }^{1}$ Graduado em Direito pelo Centro Universitário Dr. Leão Sampaio. Tabelião Interino do Cartório de Araripe/ Pernambuco. Pesquisadorvoluntário do Laboratório Interdisciplinar de Estudos da Violência (LIEV)/UNILEÃO. E-mail: jhfilho.uk@live.com

${ }^{2}$ Doutor em Sociologia pelo Programa de Pós-Graduação em Sociologia da Universidade Federal de Pernambuco. Mestre em Educação Intercultural e Antropologia Social (Universidade de Hamburgo - Alemanha). Mestre em Criminologia e Direito Internacional Público (Universidade de Hamburgo - Alemanha). Professor efetivo auxiliar do curso de Adminstração da Universidade de Pernambuco (UPE). Professor substituto do curso de Direito da Faculdade de Ciências Humanas do Sertão Central (FACHUSC). Professor horista do curso de Direito do Centro Universitário Dr. Leão Sampaio (UNILEÃO). Pesquisador-líder do Laboratório Interdisciplinar em Estudos da Violência no Centro Universitário Dr. Leão Sampaio (LIEV-UNILEÃO). Advogado. Licenciado em Pedagogia pela Faculdade Kurios (FAK). E-mail: crioulo.miguelangelo.melo@gmail.com.

${ }^{3} \mathrm{O}$ estudo é resultado de trabalho de conclusão de curso e não teve financiamento externo, uma vez que foi todo realizado com patrocínio dos autores.
}

730 Id on Line Rev. Mult. Psic. V.12, N. 40. 2018 - ISSN 1981-1179

Edição eletrônica em http://idonline.emnuvens.com.br/id 


\section{Considerações Iniciais}

A presente pesquisa tem como tema a análise da prática da mutilação genital feminina e seus reflexos na contemporânea sociedade jurídica internacional. As premissas que fundamentam o trabalho investigativo encontram espaço nos discursos e nos debates proferidos por distintas abordagens na Teoria Geral dos Direitos Humanos, sob o foco da universalidade e da relatividade dos direitos e de tais práticas culturais.

Portanto, faz-se necessário preconizar, com o intuito de definição da delimitação do tema, a conceituação de mutilação genital feminina (MGF), em que consiste, em quais locais se procede com tal processo, averiguar os contributos que levam a essa prática e as consequências da mutilação na vida das mulheres. A mutilação, também conhecida como circuncisão feminina, consiste em um processo pelo qual é extirpado, total ou parcialmente, o órgão genital feminino. Notadamente, essa prática é associada ao continente africano, sendo mais comum no Norte deste território, entretanto, como o fluxo migratório, esse ato tem se alastrado por diversos outros países pelo mundo. Perceptivelmente, ocorre entre meninas até quinze anos de idade, entretanto, pode também ocorrer em mulheres adultas, casadas ou não, visto ser, tal procedimento, um valor de inserção social.

Neste contexto, esta pesquisa efetua uma análise sobre em que níveis essa prática afronta os direitos humanos e sua relação cultural, buscando discutir as interfaces entre as abordagens universalistas e relativistas sobre essa égide, bem como os conflitos dessa reflexão com corte genital feminino, problematizando sua prática. Vale ressaltar que o principal objetivo, o qual se logra atingir, integra o confrontamento da mutilação genital feminina à luz dos direitos humanos, em vista das implicações para a saúde mental e física que prática em discussão acarreta, por consistir em ofensa ao princípio basilar da dignidade da pessoa humana.

É relevante mencionar, ademais, que este estudo se justifica, primeiramente, por tratar da MGF enquanto violação a garantias mínimas da pessoa humana, questão essa que passa as margens de boa parte da sociedade, a tal passo que possibilita suscitar nesta uma relevante reflexão acerca da questão aqui em discussão. Por conta disso, torna-se imprescindível instigar a reflexão com senso crítico concernente a tal tema, pois se encontram em debate aspectos jurídicos contundentes como a violação da dignidade da mulher e o vilipêndio as garantias à saúde integral e liberdade individual frente às imposições sociais. Outrossim, este trabalho mostra-se necessário na medida em que proporciona a compreensão da mutilação genital 
feminina como problemática a ser enfrentada em busca de garantir o enfrentamento e a consequente cessação das violações de direitos. Oportunizando, dessa maneira, a fundamentação para busca e efetivação das garantias balizadas pelos direitos humanos.

Esta pesquisa fez uso de métodos qualitativos/bibliográficos como instrumentos para análise. Quanto à abordagem, esta se caracteriza como pesquisa qualitativa, através da qual será registrada a intepretação das ideias, buscando entender os problemas apresentados pelos assuntos abordados e procurando adequar soluções para essas problemáticas. (CRESWELL, 2010). O conceito pesquisa bibliográfica, segundo Severino, consiste "[...] aquela que se realiza a partir do registro disponível, decorrente de pesquisas anteriores, em documentos impressos, como livros, artigo, teses etc”. (SEVERINO, 2007, p.122). Nesta análise qualitativa, estudarse-á como o fenômeno da mutilação da genital feminina, mediante pesquisa bibliográfica, bem como buscar a compreensão desse fenômeno cultural dentro de distintos ordenamentos jurídicos pelo mundo. Buscou-se trabalhar com o levantamento do mais vasto conteúdo de registros disponível, utilizando de trabalhos científicos coerentes e satisfatórios. Apoiando-se no ponto de vista de Gil, afirma-se que "[...] a principal vantagem da pesquisa bibliográfica reside no fato de permitir ao investigador a cobertura de uma gama de fenômenos muito mais ampla do que aquela que poderia pesquisar diretamente". (GIL, 2007, p.45). Sendo este o motivo pelo qual optou-se pela pesquisa bibliográfica.

\section{Debates e Conceitos sobre a Mutilação Genital Feminina}

A mutilação da genital feminina (MGF), também chamada de circuncisão feminina, constitui extirpação total ou parcial dos órgãos genitais externos da mulher. Neste sentido, segundo a definição da Organização Mundial da Saúde a mutilação genital feminina inclui todas as intervenções que envolvam a remoção parcial ou total dos órgãos genitais femininos externos ou que provoquem leões nos órgãos genitais femininos por razões não médicas (OMS, 1997). Essa prática ocorre notavelmente entre meninas até 15 de idade, porém pode também ocorrer em mulheres adultas e casadas. A este respeito Manuela Ivone Cunha assevera que: 
As consequências nocivas possíveis de intervenções genitais subsumidas na expressão mutilação genital feminina (MGF) na saúde sexual e reprodutiva das mulheres são conhecidas e têm gerado forte mobilização [...]. (CUNHA, 2013, p. 835).

Diante de tal panorama, expresso pela autora, percebe-se que tal fato se reveste de grande vulto nos tempos atuais, embora a MGF possa ser classificada a partir de quatro tipos de mutilação, a saber: a) clitoridectomia, realizada pela remoção do clitóris e/ou do prepúcio, sendo, às vezes, uma remoção parcial e outras total); b) excisão, que consiste, além da clitoridectomia, na retirada dos pequenos lábios, podendo haver excisão dos grandes lábios); c) infibulação ou circuncisão faraônica, a qual ocorre quando há o estreitamento do orifício varginal, que é feito através de cortes e oposição dos pequenos lábios ou dos grandes lábios, podendo ocorrer juntamente com a clitoridectomia e infibulação); e, finalmente, d) a intervenção por razões não medicas no órgão genital feminino (OMS, 1997 apud. CAMPOS, 2010), como acentua Alice Frade:

\begin{abstract}
A MGF está enraizada na tradição cultural de um conjunto diversificado de comunidades. Há registos da sua prática em 28 países do continente Africano, e pontualmente, em países da península Arábica, assim como regiões da Malásia, Indonésia e Índia. Acresce-se que a MGF existe e continua a ser realizada fora dos países de origem. Há comunidades migrantes que, em países terceiros, a perpetuam como modo de manutenção da identidade cultural. (FRADE, 2007, p. 26).
\end{abstract}

Em Maria Cristina Santino (2007), vamos encontrar reflexões sobre as relações entre a imigração e a saúde da população imigrante em Loures $^{4}$, quanto a autora se debruça com a problemática da MGF em contextos de choque e dialética cultural, uma vez que a chegada de imigrantes - em grande maioria advindos das ex-colônias portuguesas em África - trouxe uma nova realidade ao ordenamento jurídico português e as organizações promotoras dos Direitos Humanos em Portugal, bem como as organizações de proteção e auxílio a imigrantes em terras portuguesas e europeias. Nota-se, frente ao exposto, que a prática torna-se, na contemporaneidade, uma questão-problema para a Teoria Geral dos Direitos Humanos, principalmente, para a sua gramática, posto que a MGF - suas características, práticas culturais e amplitude - vem gerando um grande embate teórico entre os defensores das abordagens universalistas, relativistas e multiculturalistas ${ }^{5}$ dentro da seara Direitos Humanos. A questão se dá entre as obrigações erga omnes e as normas internacionais de jus congens, as quais findam

\footnotetext{
${ }^{4}$ Cidade Portuguesa que se encontra no entorno da grande Lisboa.

${ }^{5}$ As discussões referentes a estas categorias serão, esmiuçadamente, tratadas na terceira seção deste trabalho. 
por gerar responsabilidade internacional do Estado receptor destes imigrantes em suas territorialidades:

\begin{abstract}
Tem estado em voga atualmente a noção de obrigação erga omnes no direito internacional. Nesse sentido, seriam erga omnes as obrigações a todos impostas, independente de aceitação e, por consequência, sem que seja possível objetá-las. Trata-se de normas cuja aplicação atinge a todos os sujeitos do direito internacional público, sem exceção. [...]. No que tange à responsabilidade internacional dos Estados por violação dos direitos humanos, entende-se que não somente o descumprimento de normas convencionais (tratados) acarreta a sua responsabilidade internacional, senão também o desrespeito às obrigações erga omnes de proteção, que decorem do direito internacional costumeiro. (MAZZUOLI, 2014, p. 36).
\end{abstract}

Já em relação a interseccionalidade jurídico-cultural, entre as normas que geram obrigações erga omnes com as normas internacionais de jus congens, o referido autor acrescenta que estas últimas:

[...] são hierarquicamente superiores a todas as demais normas no plano internacional e cuja noção contemporânea é mais ampla (por se tratar de normas imperativas e inderrogáveis) que a noção de obrigações erga omnes. Assim, todas as normas de jus congens comportam obrigações erga omnes, mas nem todas as obrigações dessa categoria podem ser tidas como jus congens. (PELLET, 1999 apud MAZZUOLI, 2014, p. 37).

A partir destas discussões teóricas, percebemos que o fenômeno cultural da MGF é uma questão-problema de grande interesse jurídico e de forte relevância para a sociedade internacional, para os órgãos de proteção à pessoa humana e de proteção e preservação de culturas indígenas, tribais e ancestrais. Neste sentido, entende-se que a questão da MGF está comumente associada a rituais de purificação e/ou iniciação, sendo grandes acontecimentos comemorativos para a comunidade. As meninas são instadas a serem valentes. Geralmente, quando há mutilação, nesses rituais, só é admitida a presença de mulheres. (OTTO-OYORTEY, 2007). É de grande importância entender como se procede essa prática durante as comemorações:

Às vezes se recorre a alguém com conhecimentos para aplicar um anestésico ou se ordena à menina que se sente em água fria para intumescer a região e reduzir o sangramento. No entanto, o mais frequente é que não se tome nenhuma medida para diminuir a dor. A mutilação se leva a cabo com um vidro quebrado, a tampa de uma lata, tesouras, uma navalha ou outro instrumento cortante. (PIACENTINI, 2007, p. 38) 
O procedimento de mutilação pode ocorrer no próprio domicílio da menina, ou na residência de algum parente ou vizinho, algumas vezes em centros de centros de saúde, ou ainda se $\mathrm{o}$ ato na cultura local estiver associado a alguma iniciação, pode ocorrer em algum local que é ligado ao feito, verbi gratia, margens de rio, em especial, ou árvores determinadas. Normalmente, a pessoa responsável pela mutilação, via de regra, pode ser uma anciã, curandeira tradicional, parteira, uma barbeira qualificada e, em outros contextos, uma médica. Ocasionalmente, é feita aplicação posterior ao procedimento de antissépticos comuns, ou, eventualmente, de pomadas à base de produtos naturais. Nessa situação, é possível que a menina seja levada a um local específico para recuperação se a mutilação tiver ocorrido como parte de algum ritual de iniciação. Conforme exposto, em meninas com maiores condições financeiras, o procedimento pode ser feito em hospitais com anestesia local ou geral. (SILVA, 2015). A MGF é, constantemente, considerada como quesito de inserção social, isto por algumas sociedades, de tal forma que, para garantir que as mulheres e jovens submetam-se a essa prática, são utilizados diversos mecanismos:

\footnotetext{
Mulheres não excisadas são rejeitadas para o casamento, há o divórcio para aquelas que não passaram pela MGF, canções depreciativas, exibição pública de mulheres se submetendo à MGF antes de casarem-se, propagação do medo do desconhecido através de feitiços e evocações de ancestrais. (PIACENTINI, 2007, p. 39)
}

Ao mesmo passo que as mulheres não excisadas sofrem com tal opressão, por parte da sociedade em que vivem, as que já passaram pelo procedimento são veneradas, "com o oferecimento de recompensas, reconhecimento público, celebração, presentes, respeito e prerrogativas de participar de funções sociais." (PIACENTINI, 2007). Diversos aspectos devem/ podem ser compreendidos sob a rubrica da prática em torno da Mutilação da Genital Feminina, dentre os quais merecem destaque: a mutilação por ordem religiosa, cultural, de gênero e crenças relacionadas aos órgãos sexuais femininos.

Quanto à motivação de ordem religiosa, a mutilação da genital feminina encontra-se em todo o espectro religioso, observando, desde povos muçulmanos, passando por judeus e cristãos, como assevera Carla Martingo, ao expor que "[...] as convicções religiosas têm tido um papel muito importante na continuação da prática do corte dos genitais femininos não só em África como em todos os locais onde se perpetua." (MARTIGO, 2007, p.165). A maior incidência desse fenômeno encontra-se em populações islamizadas, contudo, não há que se generalizar a referida prática dentro das comunidades muçulmanas, pelo fato de que, se tal 
preceito religioso fosse perpetrado como norma solida e inquestionável dentro dessa para o povo mulçumano, estariam todas as mulheres sujeitas à mutilação:

\begin{abstract}
Ainda que a prática possa ser encontrada entre Cristãos, Judeus e Muçulmanos, nenhum dos seus textos sagrados prescreve a mutilação genital feminina; a pratica precede tanto no Cristianismo como no Islamismo [...]. O papel desempenhado por líderes religiosos é diverso. Aqueles que apoiam a prática tendem a considera-la um ato religioso ou a encarar os esforços envidados no sentido de eliminação como uma ameaça à cultura e religião. (OMS, 1997, p. 09)
\end{abstract}

A sustentação da prática da mutilação é consistente de estruturas de poder e autoridade local, exempli gratia, líderes tradicionais da comunidades e líderes religiosos (OMS, 1997), ou ainda, como já citado, por circuncisadoras, anciãs e mesmo por profissionais da saúde. É de grande valor o que aponta Dulce de Queiroz Piacentini, ao ressaltar que "é importante registrar que o ritual não tem a ver, em princípio, com religião; sua origem remonta a tempos anteriores ao do surgimento da religião muçulmana" (PIACENTINI, 2007, p. 117).

A este respeito, Manuel Lisboa testifica que, para além da religião, diversos fatores culturais afiguram-se à gênese da perpetuação da prática da mutilação, tendo-se, a título de ilustração, fatores como uma possível preservação da virgindade e uma maior fertilidade das mulheres submetidas a esse procedimento. (LISBOA, et al, 2015). Na balia do contexto cultural, há que se conceituar o que se entende para o presente trabalho sobre o termo "cultura", uma vez que esta terminologia, por um lado, traz consigo uma amplitude de definições; por outro lado, vem sendo abordada em contextos específicos por distintas ciências, sejam elas sociais, humanas e/ ou biomédicas.

\title{
Epistemologias da Mutilação Genital Feminina sob o foco da Interculturalidade
}

Olney-Kumpel Assis (2011), ao se debruçar com a diversidade de conceitos sobre cultura, acentua que existem, nas ciências humanas e sociais, aproximadamente, 164 definições sobre cultura, sendo que, quase todas, demonstram a mesma convergência de significados, a saber: por um lado, o termo leva a interpretação da formação individual da pessoa humana "pandeia" (formação do homem), e do outro lado, a terminologia sugere a compreensão do humanitas (educação do homem), ou seja, de todo o conjunto de obras humanas advindos do processo civilizatório em torno dos modos de vida criados, adquiridos e transmitidos de uma 
geração para outra entre os membros de determinada comunidade ou sociedade. Já em Norbert Elias $(1994$; 1994b), vamos encontrar uma interessante comparação entre os termos cultura (kultur) - de origem alemã - e civilização (civilisation) - de origem francesa -, os quais, segundo o autor, servem para que possamos compreender, interpretar e explicar diferentes processos civilizatórios, tais como, por exemplo, o próprio nazismo.

Apesar de, para Norbert Elias (1994b), a terminologia civilização, ser, majoritariamente, concebida pela abordagem francesa como um todo complexo e multifacetado (fatos políticos, econômicos, religiosos, técnicos, morais e sociais) e amplo conceito de civilização, o qual expressava a ótica da sociedade ocidental, que, até a virada do século XX, acreditava ser superior às sociedades anteriores, ou às contemporâneas, desprezando os saberes advindos destas.

O Conceito de "civilização" refere-se a uma grande variedade de fatos: ao nível da tecnologia, ao tipo de maneiras, ao desenvolvimento dos conhecimentos científicos, às ideias religiosas e aos costumes. Pode-se referir ao tipo de habitações ou à maneira como homens e mulheres vivem juntos, à forma de punição determinada pelo sistema judiciário ou o modo como são preparados os alimentos. Rigorosamente falando, nada há que não possa ser feito de forma "civilizada" ou "incivilizada". Daí ser sempre difícil sumariar em algumas palavras tudo o que pode descrever como civilização. (ELIAS, 1994b, p. 23).

Diante do exposto, verifica-se que o termo civilização na perspectiva alemã, fazia ressalva a aspectos exteriores e utilitários ao cotidiano humano, uma vez que esta ideia de civilização não conseguia enxergar para além valores nacionais. Já para os franceses, o termo civilização era um instrumento para se analisar as sociedades para além da compreensão de tempo ou de territorialidade, visto que estes acreditavam que a civilização deveria ser entendida como algo que transcendesse as fronteiras nacionais francesas, interpretação esta que era totalmente refutada pelos germânicos (ELIAS, 1994), fato evidenciado no conceito germânico de cultura:

O conceito de Kultur reflete a consciência de si mesma de uma nação que teve de buscar e constituir incessante e novamente suas fronteiras, tanto no sentido político como espiritual, e repetidas vezes perguntar a si mesma: "Qual é, realmente, nossa identidade?" A orientação do conceito alemão de cultura, com sua tendência à demarcação e ênfase em diferenças, e no seu detalhamento, entre grupos, corresponde a este processo histórico. (ELIAS, 1994b, p.25). 
Ademais, há de reportar que a abordagem antropológica e/ou etnológica germânica percebia diferenças simbólicas entre ambos os termos, já que a cultura deveria ser vista como resultado de todo um processo civilizatório, o qual estivesse limitado ao tempo, ao espaço e em plena consonância com a identidade nacional alemã. Principalmente, porque, para a escola antropológica/etnológica alemã, as realizações, avanços, descobertas e sucessos de seu povo deveria ser fomentado como um simbolismo cultural e não civilizatório, uma clara oposição à escola francesa. Finalmente, percebe-se que, para o autor, a terminologia cultura surge na contramão da ideia francesa de civilização, com clareza e objetividade não de reforço, mas de negação, tendo em vista que os germânicos compartilhavam da certeza de que a cultura representaria a plenitude das verdadeiras "virtudes" que deveriam fazer parte dos valores e princípios a serem alcançados por toda e qualquer sociedade ou conjunto de indivíduos que desejassem atingir o patamar ideal, atrelando-se a outros valores e princípios, tais como "o amor à natureza e à liberdade, a exaltação solitária, a rendição às emoções do coração, sem o freio da razão fria”. (ELIAS, 1994b, p. 36).

Não obstante, observamos que estas definições são eminentemente eurocêntricas e não conseguem entender a concepção cultural não ocidental, tampouco não dominada pela ideia de civilização ocidental ideal nas palavras de Elias (1994b). Para fundamentar e permear o campo teórico em relação a esta discussão, trazemos o olhar crítico Achille Mbembe ao predomínio intelectual ocidental, quando questiona a universalidade teórico-coercitiva dos sistemas jurídicos ocidentais na esfera da cultura jurídica internacional. Segundo o filosófico africano, as comunidades internacionais não ocidentais - tais como, a africana, a latina, a asiática e a oceânica - vivenciam, desde sempre na história da humanidade, uma ditadura não apenas normativa, porém, filosófica - tanto stricto, quanto lato senso - que foi e ainda vem sendo implantada no mundo, as quais partem do estandarte "modelo padrão" ocidental que persistem em desconsiderar e descaracterizar como "civilizado", "cultural" ou de "primitiva cultura" todo um artefato simbólico não ocidental, modelos "marginais" ou que caminham à margem do que se espera de uma "sociedade civil das nações" (MBEMBE, 2015, p. 27) como acentua Mário Pontes Filho:

Achille Mbembe nos traz uma perspectiva crítica e pós-moderna do direito, onde o mesmo afirma que as epistemologias do Ocidente são as que possuem credibilidade diante à ciência. Principalmente, quando afirma que a Europa tem certeza que permanece "sendo o bairro mais civilizado do mundo, só o Ocidente inventou um 
“direito das gentes"”. (MBEMBE, 2015; apud VASCONCELOS FILHO, 2017, p. $14)$.

Perseguindo a essência do pensamento de Achilie Mbembe, bem como admitindo a sua inegável importância para o Direito, eminentemente, um teórico não eurocêntrico e opositor do predomínio das perspectivas e abordagens teóricas ocidentais, Vasconcelos Filho (2017) ressignifica sua visão crítica e, em defesa da filosofia crítica de Achille Mbembe, alega que:

Mbembe nos ensina a ideia de um "outro mundo", onde neste outro mundo prevalece o "selvagem", que por sua vez se põe contra a humanidade, desta forma este mundo diferente torna-se uma área que se estabelece fora da seara humana, como afirma o autor: "fora do espaço onde se exerce o direito dos homens". (MBEMBE, 2015; apud. PONTES FILHO, 2017, p. 16).

Seguindo esta linha de raciocínio, recorremos à socióloga, também africana, Chimamanda Ngozi Adichie (2014), por conta de esta ser feminista e mulher, é capaz de intersecionalizar a temática cultura, civilização com a problemática da mutilação genital feminina, longe das lentas focais da civilização e/ou cultura occidental. Assim, Adichie, ao tratar de sua perspectiva dofeminismo, faz referências a sua infância na África, e às várias vezes em que foi excluída de muitos processos sociais, culturais, econômicos e profissionais, simplesmente por ser mulher. Segundo a autora:

Na escola, somente os meninos podiam ser monitores de sala e a autora estende esta perspectiva, em determinado momento da vida daquelas crianças, que foram condicionadas a apenas os meninos serem os monitores de sala, vão, de forma inconsciente, acreditar fielmente que somente os homens podem poderão ocupar os cargos de chefia em uma empresa por exemplo. E se esta prática é constante, passase a tratá-la como normal. (ADICHIE, 2014, p. 31).

Diante deste debate e do choque de perspectivas filosóficas, entre as perspectivas universais, eminentemente eurocêntricas, bem como das reflexões e abordagens teóricas críticas, que defendem a concepção de que a cultura é relativa, multicultural ou intercultural, como defende Miguel Ângelo Melo (2005), recuperamos o entendimento deste autor, que será utilizado em todo o trabalho. Devido ao fato de que o este entende a cultura como um instrumento ou como meio formador do indivíduo, estando ou não em interação com seus pares, em sociedade. Nessa perspectiva, o conceito de cultura não está dissociado da ideia de civilização, principalmente, porque é nesta ótica que ocorrem os contínuos processos coletivos 
e individuais de formação cultural, os quais podem ocorrer dentro ou fora do grupo social de forma anônima, uma vez que será o próprio agrupamento social que definirá os signos, símbolos e significados que serão para eles [indivíduos do grupo] valorizados e compartilhados socioculturalmente.

Fato importante é que a concepção de civilização, para o autor, não se restringe, necessariamente, a uma adesão aos pressupostos estabelecidos pelos grupos de poder, uma vez que esta é autônoma, logo, não se prende às mais diferentes operacionalizações ou instituto de dominação. Assim, a partir destas questões trazidas, agora, torna-se possível intercalar as categorias postas com a questão-problema deste trabalho, a saber: a mutilação genital feminina. A mutilação da genital feminina é vista, nesse aspecto cultural, como uma forma de amenizar a libido das mulheres, sendo compreendida assim como um episódio que as mantêm longe da prática sexual antes do casamento e quando já em sociedade conjugal as mantêm fiéis ao cônjuge. Em face do exposto, compreende-se que a prática da MGF é um fator primordial para que se constituam bases para um relacionamento conjugal sólido, ou seja, um bom casamento. (LISBOA, et al, 2015).

Dessa forma, a mutilação da genital perpetua-se culturalmente como um valor condicional para a obtenção de um casamento em sociedades predominantemente patriarcais, baseado princípios do casamento e da família:

\footnotetext{
A transmissão da MGF/C é, deste modo, difundida entre esses grupos, comunidades ou etnias praticantes e tem vindo a ser praticada por populações em que a castidade e a fidelidade femininas são muito valorizadas socialmente enquanto associadas à "honra da família". (LISBOA, et al, 2015, p. 27).
}

Demonstra-se, com os fatos supracitados, as dimensões culturais como constituintes de um indispensável suporte dessa prática. (CAREJO; TEIXEIRA; LISBOA, 2017). A ideia de casamento, que propicia à mulher um determinado status social, perfaz-se como um dos principais motores para a propagação e perpetuação dessa prática, sendo ainda algo que envolve uma expectativa bilateral, tanto do homem, em associação à honra da família de sua futura mulher, quanto para mulher, como atestado de honra. (LISBOA, et al, 2015). Seguindo semelhante raciocínio, Carla Martigo, preciosamente, aponta que não se deve ver a temática apenas sob o foco das disposições teóricas universalistas, eminentemente ocidentais, mas a questão é de tamanha relevância humanitária, que enseja uma discussão relativista e multicultural sobre o problema, uma vez que a realização do corte da genitais no sentido de que 
“[...] integra o conjunto de crenças e saberes que são transmitidos de geração em geração, contribuindo assim, para uma preservação dos valores e tradições que são pertença de um grupo/comunidade.” (MARTIGO, 2007: p. 134).

Em consequência, nos grupos e comunidades em que há a prática do corte da genitais de forma difusa, a execução da mutilação transformou-se em fato importante da identidade cultural das mulheres e meninas, de forma tal que fazem exprimir daquelas que já passaram por esse procedimento um sentimento de orgulho, de maturidade e integração à comunidade, em detrimento desse mesmo sentimento das que ainda não tiveram suas genitais mutiladas.

\footnotetext{
É frequentemente expectável que os homens casem apenas com mulheres que tenha sido submetida à prática. O desejo de um casamento segundo os trâmites instituídos, frequentemente um fator essencial na segurança económica e social, bem como na satisfação de ideais de ser mulher e feminilidade, poderá ser responsável pela persistência da prática. (OMS, 1997: s/p.)
}

Os homens dessas comunidades, já por terem um pré-conceito formado pela cultura no qual estão submersos, detêm a expectativa de casar-se com uma mulher que já tenha seu órgão genital mutilado, desejando assim contraírem matrimônio segundo os trâmites instituídos como um fator primordial de segurança econômica e social. Detendo a ideia, consequentemente, de que, ao casar-se com uma mulher que já praticou o corte genital, ele estará casando-se com um indivíduo que será responsável pela perpetuação da pratica. Há ainda que se pontuar, preciosamente, quanto a crenças relacionadas aos órgãos sexuais femininos. Isto porque, no interior de comunidades de adotam a prática da MGF, existem diversas crenças associadas às genitais femininas que justificariam sua mutilação. Sandra Marisa Pereira Rendall Piedade, em sua tese de mestrado em Portugal, sobre a Mutilação Genital Feminina, aponta que "[...] o clitóris é considerado um órgão associado à masculinidade, sendo retirado para estabelecer uma diferenciação clara e inequívoca entre homens e mulheres." (PIEDADE, 2008, p. 6) Há que se falar em alguns grupos étnicos em que uma mulher, a qual teve sua genital cortada, é considerada mais limpa, bonita, sendo que tal procedimento, ainda, a torna mais fértil. Posteriormente, a autora pondera, ao ressaltar que:

\footnotetext{
Algumas comunidades também consideram que o clitóris aumenta a frequência de complicações no parto, nados mortos, danos físicos e psicológicos no bebé, sendo também responsável pela cegueira de quem assiste ao parto e até mesmo da morte do marido da parturiente. (PIEDADE, 2008, p. 6)
} 
Como podemos observar as motivações para fornecer suporte à continuação da mutilação são diversas, desde religiosas e culturais, a aspectos que se revelam sem fundamento, como a associação à morte do marido da gestante. Essas crenças culturais dão suporte à perpetuação da prática da mutilação pelos tempos, visto que a pressão social não é exercida apenas em face às mulheres da sociedade local, mas, de uma forma geral, acomete todos os indivíduos que fazem parte desta. Homens crescem com o entendimento de que mulheres que não passaram pelo procedimento da mutilação não são dignas. Neste segmento, observa-se que o sustento dessa prática se dá tanto culturalmente, quanto socialmente, principalmente no que diz respeito às concepções ligadas à saúde da mulher, supramencionado, a ideia de que a mulher mutilada seria mais limpa do que a mulher que não vivenciou a mutilação em seu cotidiano. Corroborando, também, o conceito de que o clitóris, de per si, e pelo fato de existir, pode causar complicações à saúde na criança. Essas concepções geram fantasmas que rondam e assustam a todos, visto a forte crença cultural em tais ideias, reformando, como dito, a perpetuação da prática da mutilação.

\section{Interseccionando os Direitos Humanos com a Mutilização Genital Femina}

Os Direitos Humanos em órbita contemporânea ostentam características intrínsecas aos que os distinguem de outros tipos de direitos, em especial, as garantias fundamentadas nos ordenamentos domésticos de cada Estado, sendo possível denominar-se características de direitos humanos relativas à sua titularidade, natureza e princípios. (MAZZUOLI, 2016). Sendo assim, os Direitos Humanos possuem caraterísticas próprias destinadas a estabelecer parâmetros e diretivas para uma organização social com base no reconhecimento da pessoa humana em si mesma e em sua própria existência. Entendendo-se a universalidade como a aplicação a todos os membros da espécie humana independentemente de qualquer atributo individual. (PORTELA, 2016). A este respeito, Valério Mazzuoli complementa, ao sugerir que:

São titulares de direitos humanos todas as pessoas, o que significa que basta ter a condição de "ser humano" para que se possa invocar a proteção desses mesmos direitos, tanto no plano interno como no plano internacional, independentemente de circunstâncias de sexo raça, credo religioso, afinidade política, status social, econômico, cultural etc. (MAZZUOLI, 2016, p. 900) 
Afirmar a universalidade dos Direitos Humanos consiste em não se requerer qualquer outra condição senão apenas a de ser humano para que possa afirmar a sua seguridade a todos os direitos atribuídos, internamente ou internacionalmente, pela ordem jurídica a todos. A historicidade é outra característica dos Direitos Humanos, pois tem-se que estes direitos são históricos, sendo, por isso, constituídos com o decorrer do tempo. Conforme trata Paulo Henrique Gonçalves Portela, "nesse sentido, tais direitos não figuram pauta fixa e estática, definida em um único momento na história, mas sim um catálogo aberto a novos direitos, que reflitam valores aos quais as sociedades venham atribuindo importância no decorrer de sua evolução" (2016, p. 821).

Outras características dos Direitos Humanos são a irrenunciabilidade, indisponibilidade, inalienabilidade. Respectivamente, tais direitos não possuem o condão de mesmo com a concordância do seu titular, pessoa humana, de serem violados, dispostos ou cedidos (onerosamente ou gratuitamente) a qualquer título pois perfazem-se em existência a uma condição do indivíduo de ser humano.

Paulo Henriques Portela aponta que a transnacionalidade consiste em "pertencer à pessoa independentemente de sua nacionalidade ou mesmo de serem apátridas" (2016, p. 821). Perfaz assim a transnacionalidade fundamento recíproco e evidente da universalidade. Já os direitos humanos não necessitam de qualquer concessão do Estado para que existam, sendo eles existentes pela própria condição do ser humano, fazendo, dessa forma, surgir outra característica: a inerência. Assim, independe os direitos humanos do reconhecimento ou concessão estatal, sendo esses direitos existentes na própria condição do homem ou mulher, ou seja, da pessoa humana. (PORTELA, 2016).

Há ainda uma característica fundamental dos Direitos Humanos, a vedação ao retrocesso. Como já dito, esses direitos advém de uma construção histórica, se perfazendo na historicidade da humanidade, no entanto, essa historicidade pode levar a uma ideia equivocada de que os Diretos Humanos se perdem no tempo. Conforme estabelece Paulo Henrique Gonçalves Portela, ao ressaltar que, “[...] a noção de historicidade dos direitos humanos não comporta a possibilidade de que as normas que consagram certos direitos desapareçam do ordenamento jurídico ou tenha seu escopo de proteção reduzido.” (PORTELA, 2016, p. 821). Nessa medida, temos, em matéria de Direitos Humanos, a característica da vedação ao retrocesso pelo qual se afirma que, uma vez positivada a norma de Direitos Humanos, esta não pode regredir, mas ser ampliada, ou seja, não pode ser extinta, apenas substituída por outra de 
maior grau protetivo. Por fim, há que frisar que essas características, aqui citadas, não se esgotam em si mesmas, são apenas um rol exemplificativo, vista a complexidade da matéria.

Com o fenômeno da globalização, que aproxima de forma cada vez mais intima as relações entre os povos do globo, proporcionando maior nitidez e destaque aos problemas enfrentados pelos Estados e suas sociedades, que, por vezes, eram marginalizados, ao ponto de esquecimento por parte das autoridades dos países. Com tal processo de aglomeração social e cultural mundial, evidenciou-se uma perspectiva objetiva à disparidade com relação aos direitos dos cidadãos em suas respectivas pátrias. Tal visão de mundo, advento da globalização, fez intensificar-se a doutrina universalista dos direitos humanos que busca estabelecer um paradigma mínimo de direitos a todos os indivíduos, conforme já assinalado. Consoante colabora Flávia Piovesan, como suas palavras, para nosso entendimento: "Para os universalistas, os direitos humanos decorrem da dignidade humana, enquanto valor intrínseco à condição humana. Defende-se, nesta perspectiva, o mínimo ético irredutível - ainda que possa se discutir o alcance deste "mínimo ético" (PIOVESAN, 2006, p. 12).

Partindo desse pressuposto, dentre os que apoiam o universalismo, há defensores de que os Direitos Humanos devem ser considerados e obedecidos, independentemente de quaisquer condições, sejam culturais, econômicas ou sociais, devem ser aceitos e seguidos por todos os indivíduos. Afirmando que o relativismo cultural seria uma forma de violar os Direitos Humanos, pois os valores culturais podem ser usados como fundamentação para contrapor valores humanos, como a vida e a liberdade. (FERREIRA, 2016).

Há, entretanto, fortes críticas a esse modelo universalista, como observamos Norberto Bobbio, que se demonstra contrário a essa concepção universalista atemporal, o que pode ser visto em suas palavras:

Do ponto de vista teórico, sempre defendi - e continuo a defender, fortalecido por novos argumentos - que os direitos do homem, por mais fundamentais que sejam, são direitos históricos, ou seja, nascidos em certas circunstâncias, caracterizadas por lutas em defesa de novas liberdades contra velhos poderes, e nascidos de modo gradual, não todos de uma vez, e nem de uma vez por todas. (BOBBIO, 1992, p. 5).

É clara a posição do autor ao ver com consideráveis ressalvas o modelo universalista atemporal, afirmando, categoricamente, o eminente perigo tal pensamento de servir como suporte para posições conservadoras. Além disso, opõe-se à fundamentação absoluta e atemporal, contudo não nega o universalismo, mas crê que a universalidade dos Direitos 
Humanos foi alcançada pela massiva ratificação da Declaração Universal dos Direitos Humanos pela comunidade internacional. Assim, ratificando a compreensão de que os direitos históricos ali mencionados devem ser protegidos em âmbito global. (BOBBIO, 1992; PAULA, 2010).

Noberto Bobbio é veemente em colocar que, em dado momento histórico, determinada posição, que é vista como Direito Fundamental, outrora pode não ser mais assim considerada, assumindo que não se deve temer o relativismo. Nesse sentido, para os relativistas, em síntese, defendem a premissa de que há um valor absoluto que transcende o tempo, para estes a noção de Diretos Humanos está diretamente interligada ao meio social, político, econômico, cultural e moral, no qual está imersa determinada sociedade em determinado período temporal. Assim, cada cultura, com base nesses aspectos e circunstâncias específicos, constrói seu próprio discurso, estando evidentemente ligado à historicidade individual de cada sociedade. (PIOVESAN 2008; PAULA, 2010; FERREIRA, 2016).

Excelente conceituação é expressa nas palavras de Elis Nobre Ferreira, no sentido de que:

\footnotetext{
O relativismo cultural dos direitos humanos é representativo do fato de que cada sociedade, por ter suas próprias crenças e princípios, pode valorizar e conceituar de forma distinta o que são os direitos humanos, ou seja, cada sociedade pode ter uma concepção individualizada desses direitos. (FERREIRA, 2016, online)
}

Conforme ratifica o autor, a concepção de relativismo se faz por essa construção própria, advinda de pilares como valores e crenças próprias de um povo sem qualquer imposição de quaisquer outros valores distantes da construção local. Os relativistas apontam várias críticas à proposta universalista dos Direitos Humanos, entre as quais afirmam que a proposta universalista estaria constituída em uma ideia antropocêntrica, o que claramente não universal em todas as culturas. Alegam ainda aqueles que o universalismo, como mencionado, em tese, tende a impor valores que podem ser distantes da cultura local, estabelecer padrões de um mundo ocidental para todo o mundo. Neste seguimento de imposição de valores, Boaventura de Sousa Santos comenta que:

[...] enquanto forem concebidos como direitos humanos universais, os direitos humanos tenderão a operar como localismo globalizado — uma forma de globalização 
de-cima-para-baixo. Serão sempre um instrumento do "choque de civilizações" [...]. (SANTOS, 2001, online) ${ }^{6}$

É claro o raciocínio do autor ao destacar a ponderação a se ter em uma concepção universalista dos Direitos Humanos, isto porque se deve ter cautela para não se impor uma globalização forçada dos Direitos Humanos, pelas grandes potências ocidentais, ou mesmo locais, tornando assim em uma espécie de direitos humanos impositivos, que, dessa forma, desvirtuar-se-iam da construção de que seriam uma essência do próprio homem. Nessa perspectiva, Fredys Sorto, em relação à Declaração Universal dos Direitos Humanos, expõe que:

[...] alega-se que ela também padece do mal do relativismo, pois é fruto das tradições culturais ocidentais que não correspondem às de outros povos. [...] O ponto é que há valores que de fato são particulares, como tais devem ser respeitados, desde que eles, naturalmente, não conflitem com os valores que são universais, que constituem o núcleo duro dos direitos humanos. (SORTO, 2002, p. 12)

Como visto na Declaração Universal dos Direitos Humanos, pode ser tida como declinada a valores culturais ocidentais específicos deste lado do meridiano, que não podem ser impostos à coletividade mundial como únicos e verdadeiros. Apesar disso, há que se observar, como afirmado por Fredys Sorto (2002), que há, de fato, valores individuais de cada sociedade e que estes devem gozar de todo respeito plausível, porém estes valores particulares devem respeitar, igualmente, valores que são intrínsecos à natureza humana, como a vida, dignidade e saúde, que constituem essência dos Direitos Humanos. Em outro aspecto, faz-se primorosa a observação de Flávia Piovesan, ao dizer que: "Na ótica relativista há o primado do coletivismo. [...] o indivíduo é percebido como parte integrante da sociedade. [...] na ótica universalista há o primado do individualismo. O ponto de partida é o indivíduo" (PIOVESAN, 2008, p. 149).

Em suma, no pensamento da autora, observa-se que, na vertente relativista, o coletivo é o centro a partir do qual emanam os valores e crenças culturais, dos quais, em tese, os Direitos Humanos, nessa concepção, deveriam resguardar por tratar-se da identidade dos povos, algo peculiar daquela coletividade específica, enquanto que sob o prisma da universalista cada indivíduo representa o valor em si mesmo na condição humana, sendo ele, independentemente

\footnotetext{
${ }^{6}$ Localismo globalizado para o autor é consiste "no processo pelo qual determinado fenômeno local é globalizado com sucesso, seja a atividade mundial das multinacionais, a transformação da língua inglesa em língua franca, a globalização do fast food americano ou da sua música popular ou a adoção mundial das leis de propriedade intelectual ou de telecomunicações dos EUA". (SANTOS, 2001, p. 13)
} 
de qualquer outros aspecto, resguardado pelos Direitos Humanos inerente a sua condição. O relativismo cultural, circunstancialmente, é usado como fundamento para defender práticas que atentam diretamente ao chamando núcleo duro dos Diretos Humanos, como denominado por Fredys Sorto (2002). Essa corrente, como já demonstrado, proclama a relativização da ideia que todos os seres humanos gozam de uma essência comum, que daria a todos, sem distinção, qualquer um linear mínimo de direitos inerentes a sua condição. Porém, essa mesma corrente não considera a ideia ou vontade de cada um, cada indivíduo, em meio a sua coletividade, suprimindo este sob a ideologia de proteção cultural, subjugando, dessa maneira, o pensamento e vontade do sujeito.

\section{Considerações Finais}

Os Direitos Humanos são aqueles direitos essenciais ao ser humano, sendo estes sujeitos desses direitos pelo simples fato de sua qualidade, sendo esses direitos inerentes à espécie humana. Todavia, há de se afirmar que, como valores básicos de cada indivíduo humano, os direitos humanos, claramente vão de encontro a qualquer ato ou processo que implique na amputação de órgãos ou tecidos perfeitamente saudáveis. Sendo assim, a mutilação da genitália feminina qualifica-se como uma afronta aos direitos das mulheres.

E como de fato a mutilação ocorre no período infante, torna-se também ofensa ao direito das crianças. Um ponto a ser levando em consideração é a questão dos valores culturais e os Direitos Humanos, como visto a cima, no debate sobre universalismo e relativismo, a questão sobre imposição de valores e relativização de práticas é algo de extremos. Contudo, sobre a ótica dos Direitos Humanos, a integridade física e psicológica, bem como a não descriminação e acesso ao melhor padrão de saúde sustentável são questões que transcendem valores, pois são universais.

Faz-se mister ressaltar que estes direitos estão especificados e possuem a adesão de diversos tratados regionais e internacionais, sendo também abrigados por um Sistema Global de Proteção. Como também, através de conferências e convenções mundiais, como, por exemplo, os desenvolvidos pelas Nações Unidas. Explicitamente, em tratados internacionais, como a Convenção sobre a Eliminação da Discriminação contra as Mulheres e Convenção sobre os Direitos da Criança, em tratados regionais, como a Carta Africana sobre Direitos Humanos 
e dos Povos e Protocolo sobre o Direitos da Mulher na África, e em documentos de consenso, tais como Declaração de Beijing e Declaração Universal da UNESCO sobre Diversidade Cultural, há um forte apoio em favor de mulheres e meninas, as quais são objetos dessa prática cultural.

Esses documentos internacionais, e muitos outros firmados, têm como supedâneo iluminar e apresentar um alicerce sólido e fecundo para que a sociedade, em conjunto com seus Estados, possa definitivamente por um ponto final às práticas culturais violadoras dos Direitos Humanos e edificar a figura do princípio norteador do sistema jurídico internacional: o princípio da Dignidade da Pessoa Humana. Ressalta-se que a Dignidade da Pessoa Humana está concatenada com outros valores, como a justiça, a vida, a liberdade, a igualdade, a segurança e a solidariedade, as quais inspiram ações concretas, dignificam os que se propõe a alcançá-los, respaldando os diversos ordenamentos jurídicos, dando concretude e respaldo ao combate a injustiças, e atos cruéis, desumanos ou degradantes.

O silêncio ensurdecedor de inúmeras mulheres e meninas clama por uma efetividade no combate à referida prática, na busca da edificação da sua dignidade enquanto ser, ser este que precisa muito mais do que proteção jurídica, mas sim acolhimento humano e de ações que as ajudem a superar e combater esse mal que assolam muitos países.

Finalmente, acrescenta-se que a teoria relativista, em contrapartida à universalista, critica essa característica universal tendenciosamente impositiva. Essa teoria observa sim garantias mínimas indistintas a cada ser humano, todavia, são levados em consideração os aspectos valorativos individuais de cada sociedade, cada comunidade.

Observa-se que, mesmo em suas distinções, ambas têm como plano de fundo garantias básicas, inerentes à individualidade ou coletividade humana, dentre essas garantias é possível citar, de modo demonstrativo, a liberdade individual, o acesso à saúde integral, não submissão à tortura ou práticas degradantes, desumanas ou cruéis.

\section{Referências}

ADICHIE, Chimamanda Ngozi. Sejamos todos feministas. Tradução de Christiba Baum. São Paulo: Companhia das Legras, 2015. 
ASSIS, Olney-KUMPEL, Vitor. Manual de Antropologia Jurídica. São Paulo: Editora Saraiva, 2011.

BOBBIO, Norberto. A era dos direitos. Rio de Janeiro: Campus, 1992.

CAMPOS, Ana Correia. Mutilação genital feminina - a importância de reconhecer e de saber como agir. Acta Obstet Ginecol Port 2010;4(3):152-156.

CEREJO, Dalila; TEXEIRA, Ana Lúcia; LISBOA, Manuela. Mutilação genital feminina. Contextos socioculturais, discursos e percepções sobre a mutilação genital feminina. 2017 p. 83-103.

CRESWELL, J. W. W. Projeto de pesquisa: métodos qualitativo, quantitativo e misto. 2. ed. Porto Alegre: Bookman, 2010.

CUNHA, Manuela Ivone. Género, cultura e justiça: A propósito dos cortes genitais. Análise Social. Edição 4. Lisboa, Portugal: 2013. Disponível na Internet: < http://www.ics.ul.pt> Acesso em: 07 mai. 2018.

ELIAS, Norbert. A sociedade dos indivíduos, Rio de Janeiro: Jorge Zahar Ed., 1994;

ELIAS, Norbert. O processo civilizador. Uma história dos costumes, v 1, Rio de Janeiro: Jorge Zahar Ed., 1994b.

FERREIRA, Elis Nobre. Teorias dos Direitos Humanos: debate entre universalismo e relativismo cultural. Conteúdo Jurídico, Brasília-DF: 30 abr. 2016. Disponível em: $<$ http://www.conteudojuridico.com.br/?artigos\&ver=2.55789\&seo=1>. Acesso em: 03 mai. 2018.

FRADE, Alice (Org.). Por Nascer Mulher... um outro lado dos Direitos Humanos. Associação para o Planeamento da Família. Lisboa, 2007.

GIL, A. C. Como elaborar projetos de pesquisa. 4. ed. São Paulo: Atlas, 2007.

MARTINGO, Carla. O corte dos genitais femininos em Portugal: o caso das guineenses. Dissertação de mestrado em Relações Internacionais, Faculdade de Ciência Política e Relações Internacionais. Universidade Aberta, Lisboa: 2007.

MAZZUOLI, Valerio de Oliveira. Curso de Direitos Humanos. São Paulo: Método, 2014.

MBEMBE, Achille. Crítica da razão negra. Tradução de Marta Lança. Portugal: Antígona, 2014.

MELO, Miguel Ângelo Silva de. Deutschsprachige Einwanderung im Rio Grande do Sul. Integration, im Spanunngsfeld von Politik und Schulwesen Sprache und kulturelle Identitaet. 2005. 156f. Dissertação (Mestrado em Ciências da Educação), Universität Hamburg, Hamburg, 2005. 
OMS; ADPF. Ace ONU (1997) Convenção Sobre a Eliminação de Todas as Formas de Discriminação Contra as Mulheres. Eliminação da mutilação Genital Feminina: Declaração conjunta OHCHR. ONUSIDA, PNUD, UNECA, Unesco, UNFPA, ACNUR, UNICEF, UNIFEM, (2008). Lisboa. Disponível em: < http://www.instituto-camoes.pt/ images/cooperacao/eliminacao_mgf_declarconjt.pdf> Acesso em: 07 mai. 2018

OTTO-OYORTEY, Naana. Mutilação Genital Feminina. Uma preocupação da Saúde e Direitos Sexuais e Reprodutivos. p. 10-15. In: FRADE, Alice (Org.). Por Nascer Mulher... um outro lado dos Direitos Humanos. Associação para o Planeamento da Família. Lisboa, 2007.

PAULA, EDUARDO LOULA NOVAIS DE. Direito Internacional dos Direitos Humanos: em busca da superação da discussão entre relativismo x universalismo. Direito UNIFACSDebate Virtual, n. 122, 2010.

PIACENTINI, Dulce de Queiroz. Direitos Humanos e Interculturalismo: Análise da Prática Cultural da Mutilação Genital Feminina. Dissertação (Mestrado em Direito) - Centro de Ciências Jurídicas, Universidade Federal de Santa Catarina, Florianópolis, 2007.

PIEDADE, Sandra Marisa Pereira Rendall. Mutilação genital feminina em Portugal. Dissertação de Mestrado em Psicologia Social e das Organizações, Departamento de Psicologia Social e das Organizações, Instituto Superior de Ciências do Trabalho e da Empresa - ISCTE, Lisboa, 2008.

PIOVESAN, Flávia. Direitos humanos: desafios da ordem internacional contemporânea. In: PIOVESAN, Flávia (Coord.). Direitos humanos. Curitiba: Juruá Editora, 2006. Vol. 1. pp. $15-37$.

PIOVESAN, Flávia. Direitos Humanos e o direito constitucional internacional. 9. ed. São Paulo: Saraiva, 2008.

PORTELA, Paulo Henrique Gonçalves. Direito Internacional Público e Privado. $8^{\text {a }}$. Edição revistado e atualizado. São Paulo: Editora Saraiva. 2016.

SANTINO, Maria Cristina. Imigração e Saúde em Loures - reflexões sobre a prática da Mutilação Genital Feminina. In: FRADE, Alice (Org.). Por Nascer Mulher... um outro lado dos Direitos Humanos. Associação para o Planeamento da Família. Lisboa, 2007.

SANTOS, Boaventura de Sousa. Para uma concepção multicultural dos Direitos Humanos. 2001. Disponível em:

$<$ http://www.boaventuradesousasantos.pt/media/pdfs/Concepcao_multicultural_direitos_hum anos_ContextoInternacional01.PDF>_Acesso em: 04 mai. 2018.

SEVERINO, Antonio Joaquim. Metodologia do Trabalho Científico. São Paulo: Cortez, 2007.

SILVA, Carina Castro da Silva. Mutilação Genital Feminina. Percepções de jovens guineenses residentes em Portugal e de profissionais com experiências em Guinea-Bissau. Dissertação (Mestrado em Sociologia). Faculdade de Ciências Sociais e Humanas, 
Universidade Fernando Pessoa de Porto, 2015. Disponível em: <https://bdigital.ufp.pt/bitstream/10284/4917/1/Carina\%20Silva\%20-

\%20Disserta\%C3\%A7\%C3\%A3o\%20FINAL.pdf >_Acesso em: 07 mai. 2018.

SORTO, Fredys Orlando. A Declaração Universal dos Direitos Humanos no seu sexagésimo aniversário. In: Verba Juris, Anuário da Pós-Graduação em Direito, ano 1, n. 1, jan./dez. 2002. João Pessoa: Editora Universitária (UFPB), 2002. p. 9-34.

VASCONCELOS FILHO, Mário Pontes de. (Des)cuidando do gênero na escola: análise crítica da heteronormatividade no legislativo sob a perspectiva dos direitos LGBT's. Trabalho de Conclusão de Curso (Graduação em Direito). Centro Universitário Dr. Leão Sampaio. Orientador Dr. Miguel Ângelo Silva de Melo, 2017.

\section{Como citar este artigo (Formato ABNT):}

ALENCAR FILHO, José Humberto de; MELO, Miguel Ângelo S. de. Discursos Sobre a Mutilação Genital Feminina e Seus Reflexos na Contemporânea Sociedade Jurídica Internacional. Id on Line Rev.Mult. Psic., 2018, vol.12, n.40, p.730-751. ISSN: 1981-1179.

Recebido: $16 / 05 / 2018$

Aceito 18/05/2018 